\title{
Dynamics and Responses of Vegetation to Climatic Variations in Ziya- Daqing Basins, China
}

\author{
HUANG Farong ${ }^{1,2}$, MO Xingguo ${ }^{1}$, LIN Zhonghui ${ }^{1}$, HU Shi ${ }^{1}$ \\ (1. Key Laboratory of Water Cycle and Related Land Surface Processes, Institute of Geographical Sciences and Natural Resources Re- \\ search, Chinese Academy of Sciences, Beijing 100101, China; 2. University of Chinese Academy of Sciences, Beijing 100049, China)
}

\begin{abstract}
Examining the direct and indirect effects of climatic factors on vegetation growth is critical to understand the complex linkage between climate change and vegetation dynamics. Based on the Moderate Resolution Imaging Spectroradiometer (MODIS) Normalized Difference Vegetation Index (NDVI) data and meteorological data (temperature and precipitation) from 2001 to 2012 , the trend of vegetation dynamics were examined in the Ziya-Daqing basins, China. The path analysis was used to obtain the information on the relationships among climatic factors and their effects on vegetation growth. It was found that the trends of growing season NDVI were insignificant in most plain dry land, while the upward trends were significant in forest, grass and dry land in Taihang Mountains. According to the path analysis, in $23 \%$ of the basins the inter-annual NDVI variation was dominated by the direct effect of precipitation, in $5 \%$ by the direct effects of precipitation and temperature, and in less than $1 \%$ by the direct effect of temperature or indirect effects of these two climatic factors. It indicated that precipitation significantly affected the vegetation growth in the whole basins, and this effect was not regulated by temperature. Precipitation increase (especially in July, August and September) was favorable to greenness enhancement. Summer temperature rising showed negative effect on plant productivity enhancement, but temperature rise in April was beneficial for the vegetation growth. When April temperature increases by $1{ }^{\circ} \mathrm{C}$, the onset date of greenness for natural vegetation will be 2 days in advance. There was a lag-time effect of precipitation or temperature on monthly NDVI for all land use types except grass.
\end{abstract}

Keywords: Normalized Difference Vegetation Index (NDVI); phenology; climate variation; direct effect; indirect effect

Citation: Huang Farong, Mo Xingguo, Lin Zhonghui, Hu Shi, 2016. Dynamics and responses of vegetation to climatic variations in Ziya-Daqing basins, China. Chinese Geographical Science, 26(4): 478-494. doi: 10.1007/s11769-016-0807-0

\section{Introduction}

Climate exerts the dominant control on the spatial distribution of plant species on the global scale. Characterized by the variations of temperature and precipitation, climate variability and change has had a profound effect on dynamics and spatial pattern of vegetation. Simultaneously, vegetation plays a critical role in regulating the earth's climate through altering the physical characteristics of land surface such as albedo, roughness, water conductivity and atmospheric gas composition. There- fore, it is widely accepted that vegetation is a sensitive indicator of climate change. Many scholars have sought to detect the vegetation dynamics and explore its climatic mechanism (Gurgel and Ferreira, 2003; Matthews et al., 2004; Xu and Liu, 2007; Jedrzejek et al., 2013).

The response of vegetation to climate change is complex and shows variations in different locations and over time. Generally, precipitation is the limiting factor for plant growth in the arid and semi-arid areas across the globe (Kawabata et al., 2001; Fensholt et al., 2012), while temperature is the restricted factor in the high

Received date: 2015-09-01; accepted date: 2015-12-03

Foundation item: Under the auspices of National Natural Science Foundation of China (No. 41471026, 31171451), Strategic Science and Technology Program in the Thirteenth Five-Year Plan of Institute of Geographical Sciences and Natural Resources Research, Chinese Academy of Sciences (No. 2012ZD003)

Corresponding author: MO Xingguo. E-mail: moxg@igsnrr.ac.cn

(C) Science Press, Northeast Institute of Geography and Agroecology, CAS and Springer-Verlag Berlin Heidelberg 2016 
latitudes of north hemisphere and Qinghai-Tibet Plateau (Zhou et al., 2001; Li et al., 2015). Over the whole China, the long-term variation of Normalized Difference Vegetation Index (NDVI) is determined by the persistence of above or below average temperature, but that of the short term is controlled by precipitation (Meng et al., 2011). In addition, the effects of temperature and precipitation on vegetation are closely related to land use type, soil types and human management practices (Yang et al., 2006; Cao et al., 2011; Chuai et al., 2013). To deeply understand the response of vegetation to climate variability and change, the location specific case study with correlated variables is still necessary.

Ground based measurements are difficult to use for detecting and predicting vegetation dynamics on the regional or global scale, because such data are collected at small spatial and temporal scales and varies in data types and reliabilities. Satellite imagery is now considered to be a goldmine to study the relationship between vegetation dynamics and climate change with the ability to capture the characteristics of temporal dynamics and spatial heterogeneity of vegetation response to climate change at fine enough spatial resolutions (Kerr and Ostrovsky, 2003). Remotely sensed NDVI can indicate the growth status, phenology and coverage of vegetation (Reed et al., 1994; Gutman and Ignatov, 1998; Yang et $a l ., 1998)$. It has been widely used to monitor the vegetation dynamics (Kinyanjui, 2011; Wylie et al., 2012) and vegetation response to climate change (Olsson et al., 2005; Cui et al., 2012).

The lag-time effect of vegetation responses to climatic variations is widely observed and depends on vegetation types and growth phases (Wang et al., 2001; Revadekar et al., 2012). For example, for the broadleaf forest in Inner Mongolia of China, summer NDVI responds to spring precipitation significantly, while the lag-time effect of summer precipitation on autumn NDVI is not significant (Chuai et al., 2013). For the same vegetation type, the length of lag time shows variations in different regions. For instance, NDVI lags behind the rainfall for one month in Africa savanna (Chamaille-Jammes et al., 2006), but for temperate steppe and desert steppe in China a time lag of three months exists between NDVI and precipitation (Piao et al., 2006).

Vegetation phenology is a sensitive indicator of climate change (Menzel and Fabian, 1999). The spring phenology is closely correlated with temperature, while the temperature sensitivity exhibits substantial variability for various vegetation types in different regions (Wang et al., 2015a). Further, the linkage between phenology and precipitation must be taken into account (Shen et al., 2011). For example, the onset of vegetation greenness closely follows the start of rain season in Africa (Zhang et al., 2005) and the pattern of vegetation phenological response to air warming is limited by water limitations before the growing season in Mongolian steppes (Yu et al., 2003).

Moreover, the effect of one climatic variable on vegetation growth may via other climatic variables. For example, precipitation will decrease temperature, which is not good for vegetation growth in Northeast Inner Mongolia (Chuai et al., 2013). Global warming decreased precipitation in North China (Zhang et al., 1994), which might be unfavorable for vegetation growth there. However, in present studies, the simple and partial correlation coefficients were mainly utilized to investigate the impact of climatic factors on vegetation growth (Wang et al., 2003; Piao et al., 2006; Mu et al., 2012; Cong et al., 2013; Wang et al., 2014; Wang et al., 2015a), the direct effect of one climatic factor on vegetation growth and the indirect effect of this climatic factor via other climatic factors were seldom quantified (Sun et al., 2005).

Owing to the complex interaction between climate and vegetation, it is still a critical issue to quantify the effects of climatic variability on the vegetation in specific areas. The Ziya-Daqing basins are in the semi-arid and semi-humid area, where evapotranspiration is the major component of water balance and prosperous vegetation growing will accelerate this vertical water flux and possibly mitigate the surface runoff in wet years (Montaldo et al., 2005). It is important to detect the vegetation response to climatic variations in this water scarcity area. In relevant researches about this area, the area where the vegetation growth was primarily impacted by climate factors was identified by partial and multiple correlation coefficients (Wang et al., 2014), and the relationship between vegetation productivity and climatic factors were examined mainly through the simple correlation coefficient, linear regression and analysis of variance (Tao et al., 2006; Yang et al., 2006; Chen et al., 2011). However, the direct and indirect effects of climatic factors on vegetation productivity were not 
quantified.

In this paper, the area where the vegetation growth was dominated by the direct and indirect effects of temperature and precipitation were examined after the vegetation dynamics were investigated during 20012012 in the Ziya-Daqing basins. To further detect the vegetation response to climatic variations in this area, the lag-time effect of temperature and precipitation on NDVI and the sensitivity of phenology to these two climatic factors were also examined.

\section{Materials and Methods}

\subsection{Study area}

In this study, the Ziya-Daqing basins $\left(36^{\circ} 07^{\prime}-40^{\circ} 16^{\prime} \mathrm{N}\right.$, $\left.112^{\circ} 03^{\prime}-116^{\circ} 39^{\prime} \mathrm{E}\right)$ are selected as the study area. It is located in the mid-west of Haihe Basin, with an area of $81600 \mathrm{~km}^{2}$ (Fig. 1). The west is among the Taihang Mountains and the east is in the North China Plain (NCP). A temperate monsoon climate prevails in the study area, with hot summer and cold winter. The mean annual temperature is about $10^{\circ} \mathrm{C}$. The annual precipitation ranges from 400 to $600 \mathrm{~mm}$ and $70 \%-80 \%$ falls in June, July and August. According to the land use data from Landsat Thematic Mapper (TM) images in 2000 (http://www.resdc.cn), the land use types (Fig. 1b) are mainly consisted of plain dry land (dry land in a plain area; $39 \%$, ratio to the total study area), grass $(24 \%)$, forest (18\%), built-up land (8\%), hilly dry land (dry land in a hilly area, 6\%), mountain dry land (dry land in a mountain area, $3 \%)$ and water area $(2 \%)$. In this paper, dry land refers to the cropland for cultivation without water supply and irrigation facilities, cropland that has water supply and irrigation facilities and planting dry farming crops, cropland planting vegetables or fallow land. Moreover, the grass contains dense grass (9\%) with coverage fraction $>50 \%$, moderate grass $(8 \%)$ with coverage fraction $5 \%-20 \%$ and sparse grass $(7 \%)$ with coverage fraction $<5 \%$. The forest includes woods $(6 \%)$ with coverage fraction $>30 \%$, shrub $(9 \%)$ with coverage fraction $>40 \%$, sparse woods $(2 \%)$ with coverage fraction $10 \%-30 \%$ and other woods $(1 \%)$.

\subsection{Data}

The NDVI images from 2001 to 2012 were acquired from National Aeronautics and Space Administration Earth Observing System (NASA/EOS) Moderate Resolution Imaging Spectroradiometer (MODIS) data product MOD13Q1, with a spatial resolution of $250 \mathrm{~m}$ and a temporal resolution of 16 days interval. In order to remove the effect of cloud and other atmospheric conditions, for each pixel the NDVI time series was smoothed

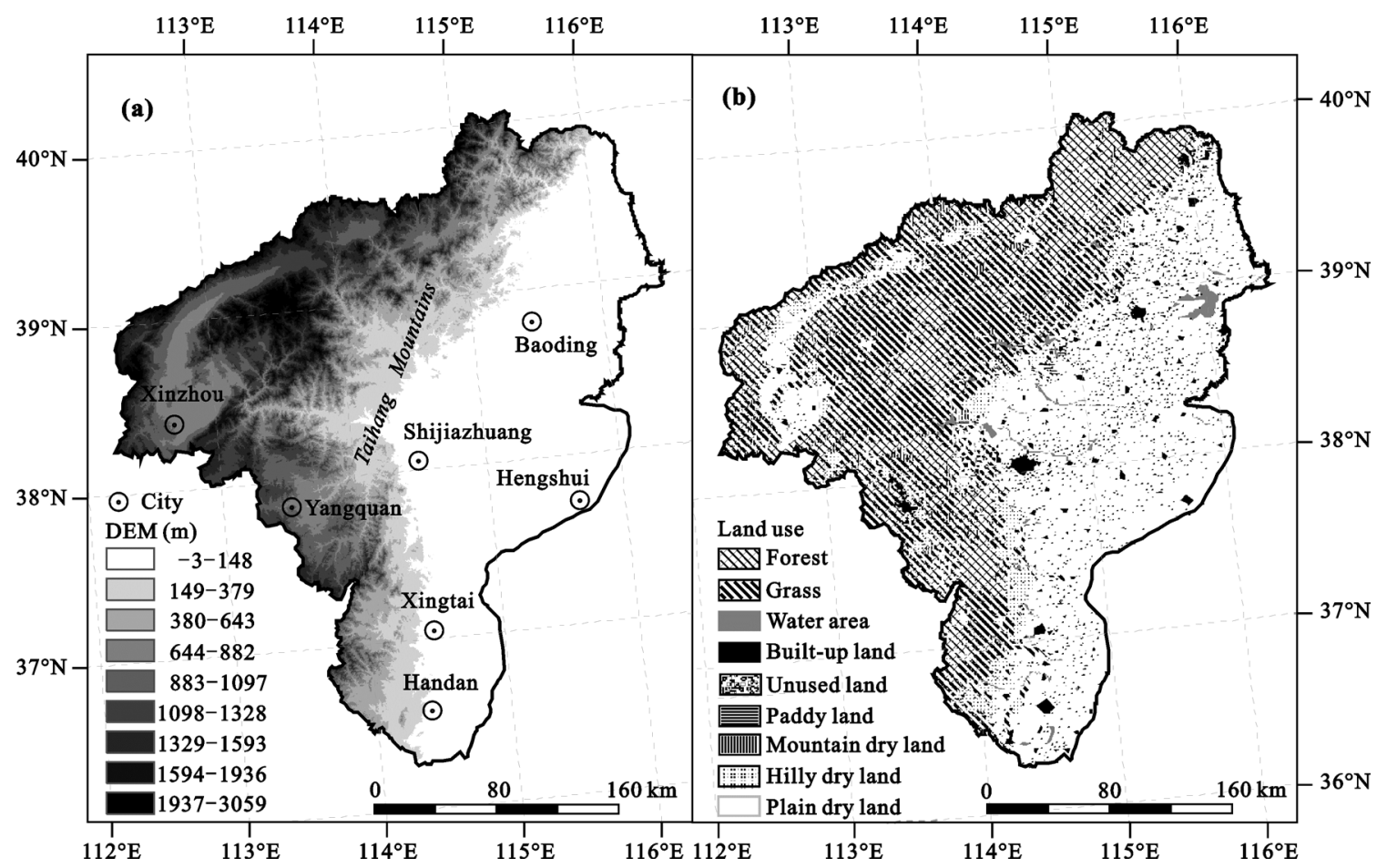

Fig. 1 Digital Elevation Model (DEM) (a) and land use (b) in Ziya-Daqing basins 
by the Savitzky-Golay (S-G) filter (Savitzky and Golay, 1964). To further reduce residual atmospheric and bidirectional effects, the maximum NDVI during a month was defined as the monthly NDVI (Piao et al., 2006). In this study, annual mean NDVI was derived by computing the average of monthly NDVI in the growing season (April to September) to eliminate the effect of bare soil. Further, for the plain dry land in the NCP, the growing season was divided into winter wheat growing season from April to May and summer maize growing season from June to September.

The meteorological data included the daily average temperature and precipitation of 78 meteorological stations in and around the study area (http://cdc.cma.gov. cn), and each year the stations which lacked data were excluded. Based on Gradient plus Inverse Distance Squared (GIDS) interpolation method (Lin et al., 2002), the spatial patterns of these two climatic variables with a spatial resolution of $250 \mathrm{~m}$ were constructed.

\subsection{Method}

\subsubsection{Analysis of vegetation dynamics}

The trend of annual mean NDVI from 2001 to 2012 was calculated by the linear regression, and the significance of the trend was derived based on $F$ test. The abrupt change of annual mean NDVI was explored based on the sequential version of Mann-Kendall test (Sneyers, 1975). The possible NDVI variation in the future was investigated by Hurst exponent $(H)$.

The $H$ is an approach to quantitatively detect the long-memory behavior of a time series (Hurst, 1951). The value of $H$ varies from 0 to 1 . The $H$ value of 0.5 means the time series is a stochastic series without consistency. The $H$ value greater than 0.5 indicates the consistency persists in the time series and implies the same change trend in the future, with the greater value for the higher consistency. The $H$ value less than 0.5 refers to anti-consistency of the time series and indicates an opposite change trend in the future, with the less value for the higher anti-consistency.

The $H$ can be calculated based on the absolute value method (Taqqu et al., 1995), aggregated variance method (Tomsett and Toumi, 2001), rescaled range (R/S) method (Sánchez Granero et al., 2008) and the variance of residuals method (Montanari et al., 1999). Here the aggregated variance method was used to look for persistence in the NDVI series, for this method works well on shorter series (Tomsett and Toumi, 2001). The first step in applying the aggregated variance method is to divide a series $X_{i}(i=1,2, \ldots, N)$ into $N / m$ no overlapping blocks of size $m$. The average value of block $k$, namely $X_{m}(k)$, is expressed as,

$$
X_{m}(k)=\frac{1}{m} \sum_{i=(k-1) m+1}^{k m} X(i)
$$

The sample variance of these means, $\operatorname{Var} X_{m}$, is calculated and the entire process repeated for different block size $m$. There is a linear relationship between $\log \left(\operatorname{Var} X_{m}\right)$ and $\log (m)$, and $H$ can be derived from Equation (2).

$$
H=(\alpha / 2)+1
$$

where $\alpha$ is the slope of this fitted line.

\subsubsection{Effect of temperature and precipitation on NDVI}

In order to quantify the direct and indirect effects of temperature or precipitation on vegetation growth, the direct effect of temperature on NDVI $\left(A_{\mathrm{t}}\right)$, indirect effect of temperature via precipitation on $\operatorname{NDVI}\left(A_{\mathrm{tp}}\right)$, direct effect of precipitation on NDVI $\left(A_{\mathrm{p}}\right)$ and indirect effect of precipitation via temperature on NDVI $\left(A_{\mathrm{pt}}\right)$ were calculated based on the path analysis. Further, in order to obtain the contribution of temperature and precipitation variations to vegetation dynamics, the combined effect of these two factors on NDVI $\left(R_{t}\right)$ was also calculated. Moreover, in order to get the primary climatic factor that affected the vegetation growth, the relationships between those effects aforementioned were examined.

According to the principle of path analysis (Fang and He, 2003; Zhang et al., 2014), the correlation coefficient $\left(r_{j y}\right)$ between the independent variable $x_{j}(j=1,2, \ldots, n)$ and dependent variable $y$ can be divided into the direct effect of $x_{j}$ on $y\left(b_{j}\right)$ and indirect effect of $x_{j}$ on $y$ via other independent variable $x_{k}\left(r_{j k} b_{k}\right)$.

$r_{j y}=b_{j}+\sum_{k=1}^{n} r_{j k} b_{k}$

where $k /=j, n$ is the number of independent variables, $r_{j k}$ is the correlation coefficient between $x_{j}$ and $x_{k}, b_{k}$ is the direct effect of $x_{k}$ on $y$. The direct effect $b_{j}(j=1$, $2, \ldots, n)$ can be acquired from Equation (4).

$y_{\text {stad }}=\sum_{j=1}^{n} b_{j} x_{\text {stad } j}+\varepsilon_{y}$ 
where $\varepsilon_{y}$ is the residual error, $y_{\text {stad }}$ and $x_{\text {stad }, j}$ are the standardized $y$ and $x_{j}$, which can be acquired from Equation (5).

$V_{\text {stad }}=\frac{V-V_{m}}{\sigma_{V}}$

where $V$ may be $y$ or $x_{j}, V_{\text {stad }}$ is the standardized $V, V_{m}$ and $\sigma_{V}$ are the average and standard deviation of $V$, respectively. Further, the multiple correlation coefficient $\left(R_{y}\right)$ between $y_{\text {stad }}$ and $x_{\text {stad } j}(j=1,2, \ldots, n)$ represents the contribution of all independent variables to the variation of dependent variable.

Thus, the correlation coefficient $\left(r_{\text {tndvi }}\right)$ between NDVI and temperature can be divided into the direct effect of temperature on NDVI $\left(A_{\mathrm{t}}\right)$ and indirect effect of temperature via precipitation on NDVI $\left(A_{\mathrm{tp}}\right)$,

$r_{\mathrm{t} n d v i}=A_{\mathrm{t}}+A_{\mathrm{tp}}$

The correlation coefficient $\left(r_{\mathrm{p} n d v i}\right)$ between NDVI and precipitation is divided into the direct effect of precipitation on NDVI $\left(A_{\mathrm{p}}\right)$ and indirect effect of precipitation via temperature on $\operatorname{NDVI}\left(A_{\mathrm{pt}}\right)$.

$r_{\mathrm{p} n d v i}=A_{\mathrm{p}}+A_{\mathrm{pt}}$

The direct effect of temperature $\left(A_{\mathrm{t}}\right)$ and precipitation $\left(A_{\mathrm{p}}\right)$ on NDVI can be obtained by the following multiple linear regression,

$$
N D V I_{\text {stad }}=A_{\mathrm{t}} \times T_{\text {stad }}+A_{\mathrm{p}} \times P_{\text {stad }}+\varepsilon
$$

where $\varepsilon$ refers to the residual error, $N D V I_{\text {stad, }}, T_{\text {stad }}$ and $P_{\text {stad }}$ represent the standardized NDVI, temperature and precipitation.

The indirect effects of temperature $\left(A_{\mathrm{tp}}\right)$ and precipitation $\left(A_{\mathrm{pt}}\right)$ can be acquired according to equations (9) and (10).

$$
\begin{aligned}
& A_{\mathrm{tp}}=r_{\mathrm{tp}} \times A_{\mathrm{p}} \\
& A_{\mathrm{pt}}=r_{\mathrm{tp}} \times A_{\mathrm{t}}
\end{aligned}
$$

where $r_{\text {tp }}$ is the correlation coefficient between temperature and precipitation.

For the direct and indirect effects of temperature $\left(A_{\mathrm{t}}\right.$ and $A_{\mathrm{tp}}$ ) or precipitation ( $A_{\mathrm{p}}$ and $A_{\mathrm{pt}}$ ), assuming

$$
\begin{aligned}
& \alpha_{\mathrm{t}}=\frac{A_{\mathrm{t}}}{\left|A_{\mathrm{t}}\right|+\left|A_{\mathrm{tp}}\right|} \\
& \alpha_{\mathrm{p}}=\frac{A_{\mathrm{p}}}{\left|A_{\mathrm{p}}\right|+\left|A_{\mathrm{pt}}\right|}
\end{aligned}
$$

If $-1 \leq \alpha_{\mathrm{t}}<-0.5$, the direct effect of temperature $\left(A_{\mathrm{t}}\right)$ is negative and greater than the indirect effect of temperature $\left(A_{\mathrm{tp}}\right)$. If $\alpha_{\mathrm{t}}=-0.5, A_{\mathrm{t}}$ is negative and comparable to $A_{\text {tp }}$. When $-0.50<\alpha_{\mathrm{t}}<0, A_{\mathrm{t}}$ is negative and smaller than $A_{\mathrm{tp}} . \alpha_{\mathrm{t}}=0$ indicates $A_{\mathrm{t}}$ is weak. $0<\alpha_{\mathrm{t}}<$ 0.5 indicates $A_{\mathrm{t}}$ is positive and smaller than $A_{\mathrm{tp}} . \alpha_{\mathrm{t}}=$ 0.5 indicates $A_{\mathrm{t}}$ is positive and comparable to $A_{\mathrm{tp}}$. 0.5 $<\alpha_{\mathrm{t}} \leq 1$ indicates $A_{\mathrm{t}}$ is positive and greater than $A_{\mathrm{tp}} . \alpha_{\mathrm{t}}$ or $\alpha_{\mathrm{p}}$ is defined as the relative effect of temperature or precipitation.

The combined effect of temperature and precipitation on NDVI $\left(R_{t}\right)$, namely the multiple correlation coefficient between NDVI and temperature and precipitation, can be obtained through Equation (8). Moreover, the significance of $A_{\mathrm{t}}, A_{\mathrm{p}}, r_{\mathrm{t} n d v i}, r_{\mathrm{p} n d v i}$ and $R_{t}$ are obtained from $F$ test, and when $R_{t}$ is significant, the path analysis is effective.

\subsubsection{Method for identifying onset and cessation date of greenness for natural vegetation}

Vegetation phenology can be retrieved from satellite NDVI by dynamic threshold method (White et al., 1997), smoothed moving average method (Schwartz et al., 2002) and curve fitting models (Myneni et al., 1998). In this paper, the dynamic threshold method (White et al., 1997; Yu et al., 2010; Cong et al., 2013; Wang et al., 2015a) was used to identify the onset (leaf expansion, grass green-up) and cessation (leaf abscission, grass brown-off) dates of greenness for natural vegetation. The dynamic threshold of NDVI $\left(N D V I_{c u t}\right)$ was described as follows.

$N D V I_{\text {cut }}=\frac{N D V I_{\max }+N D V I_{\min }}{2}$

where $N D V I_{\max }$ and $N D V I_{\min }$ were the maximum and minimum daily NDVI of each year, and daily NDVI time series was acquired by the Lagrange interpolation formula (Cong et al., 2013). Based on the dynamic threshold method, the first day (Julian day) when daily NDVI was larger than or equal to $N D V I_{c u t}$ was the onset date. From the day of $N D V I_{\max }$, the first day when daily NDVI was smaller than or equal to $N D V I_{\text {cut }}$ was the cessation date. In order to reduce the error, it was conducted only for the pixels of forest and grass with land use fraction of $100 \%$. For these cells, by computing the average, the onset and cessation dates of natural vegetation over the whole area were obtained. 


\section{Results and Analyses}

\subsection{Vegetation dynamics}

\subsubsection{Multi-year mean NDVI}

Over the whole study area, the average value of multiyear mean NDVI $\left(N D V I_{\mathrm{m}}\right)$ from 2001 to 2012 was 0.57 (Fig. 2c). The area with $N D V I_{\mathrm{m}}$ above 0.7 took up 34\% of the basins, including the mid-western area composed of arbor and shrub and the area in the NCP with dualcropping system (winter wheat and summer maize). The area with $N D V I_{\mathrm{m}}$ below 0.6 took up $23 \%$ of the basins, including the transition zone from Taihang Mountains to the NCP, Xinzhou Basin (northwest narrow strip) with single-cropping system and the area in the NCP with vegetables, cotton and oil plants. The average value of the coefficient of variation (CV) for annual mean NDVI was 0.06 (Fig. 2d). The spatial patterns of $\mathrm{CV}$ and $N D V I_{\mathrm{m}}$ were reverse. Namely, in the area where $N D V I_{\mathrm{m}}$ was higher CV was lower, and vice versa (Fig. 2). The relationship between $\mathrm{CV}$ and $N D V I_{\mathrm{m}}$ was shown in Fig. 3. It demonstrated that in the area with higher NDVI the fluctuation of vegetation greenness was smaller, and in the area with lower NDVI the fluctuation was greater. Most area with lower NDVI was around the city due to urban expansion in the recent decade (Hao, 2010). Moreover, since irrigation could not be guaranteed, NDVI fluctuation was also greater for the dry land around Xinzhou Basin.

\subsubsection{Trend of annual mean NDVI}

The spatial heterogeneity for the trend of annual mean NDVI was obvious (Fig. 4). In most areas of the basins, the trend of NDVI during 2001-2012 was not significant $(P>0.05)$. In the mid-east edge and western Taihang Mountains, NDVI showed significant positive trend (trend $>0, P<0.05$ ), accounting for $29 \%$ of the basins. Around the city, such as Shijiazhuang, since farmland changed into built-up land (Chen et al., 2011), the trend of NDVI was negative and significant (trend $<$ $0, P<0.05$ ), with area ratio of $4 \%$. According to the study by Wang et al. (2014), in $20 \%$ of the Haihe River Basin the vegetation degraded during 1998-2011. Obviously, the percent of the area where NDVI decreased

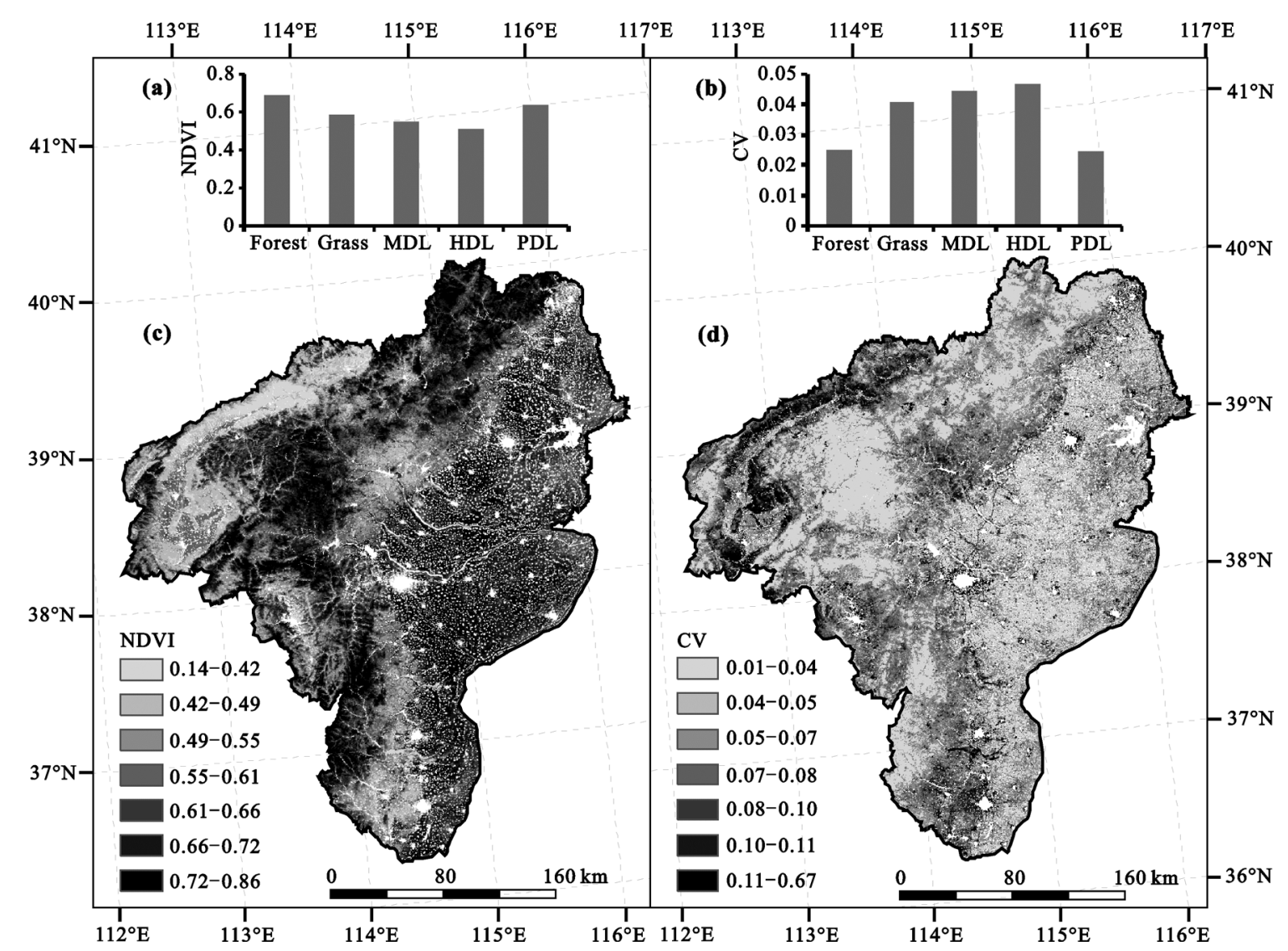

Fig. 2 Average (a, c) and coefficient of variation (CV) (b, d) of annual mean NDVI during 2001-2012. The blank area is water or built-up land, and that in the Fig. 4 and Fig. 8 are similar. MDL, HDL and PDL refer to mountain, hilly and plain dry land, respectively 


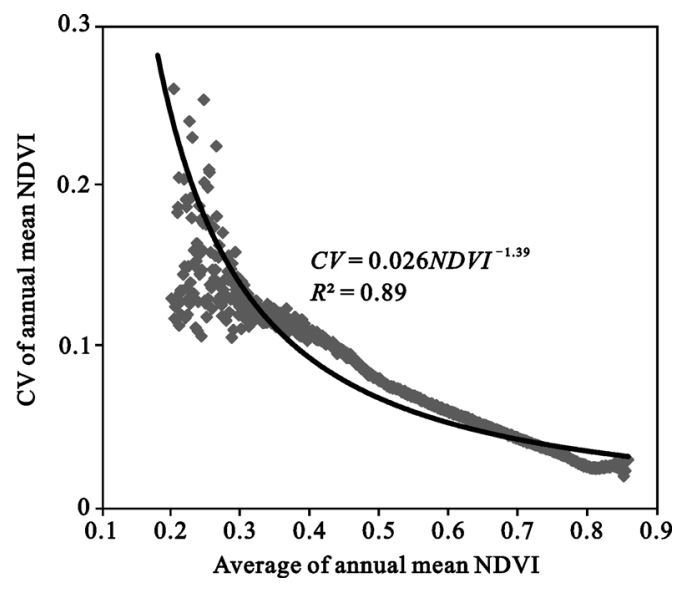

Fig. 3 Relationship between average and coefficient of variation (CV) of annual mean NDVI

was larger in the whole Haihe River Basin, partly because the urban expansion was more violent in other parts of Haihe River Basin, such as the area around Beijing.

The ratio of the area with significant NDVI trend $(P$ $<0.05)$ to the total area of each land use type was different, with the order being plain dry land $(26 \%)<$ forest
$(35 \%)<$ hilly dry land $(38 \%)<$ grass $(54 \%)<$ mountain dry land (56\%). Moreover, the ratios of the area with significant upward trend (trend $>0, P<0.05$ ) for plain dry land, forest, hilly dry land, grass and mountain dry land were $16 \%, 33 \%$ (20\% from shrub), 36\%, 51\% (14\%, 20\% and 17\% from dense, moderate and sparse grass) and $54 \%$, and the values for significant downtrend (trend $<0, P<0.05$ ) were $10 \%, 2 \%, 2 \%, 2 \%$ and $2 \%$, respectively. For plain dry land, assuming the significant downward trend within $5 \mathrm{~km}$ of the city was caused by urbanization, the ratio of this kind of area to the total area of plain dry land was about $5 \%$, which indicated that approximately $5 \%$ of the plain dry land changed into built-up land during 2001-2012 and half of the NDVI decrease area for plain dry land was caused by urban expansion.

The NDVI trend for each land use type was also different. Except for plain dry land, NDVI of all other land use types showed significant trend. The order of NDVI increasing rate was plain dry land $<$ forest $<$ hilly dry land $<$ grass $<$ mountain dry land (Table 1 ), which was

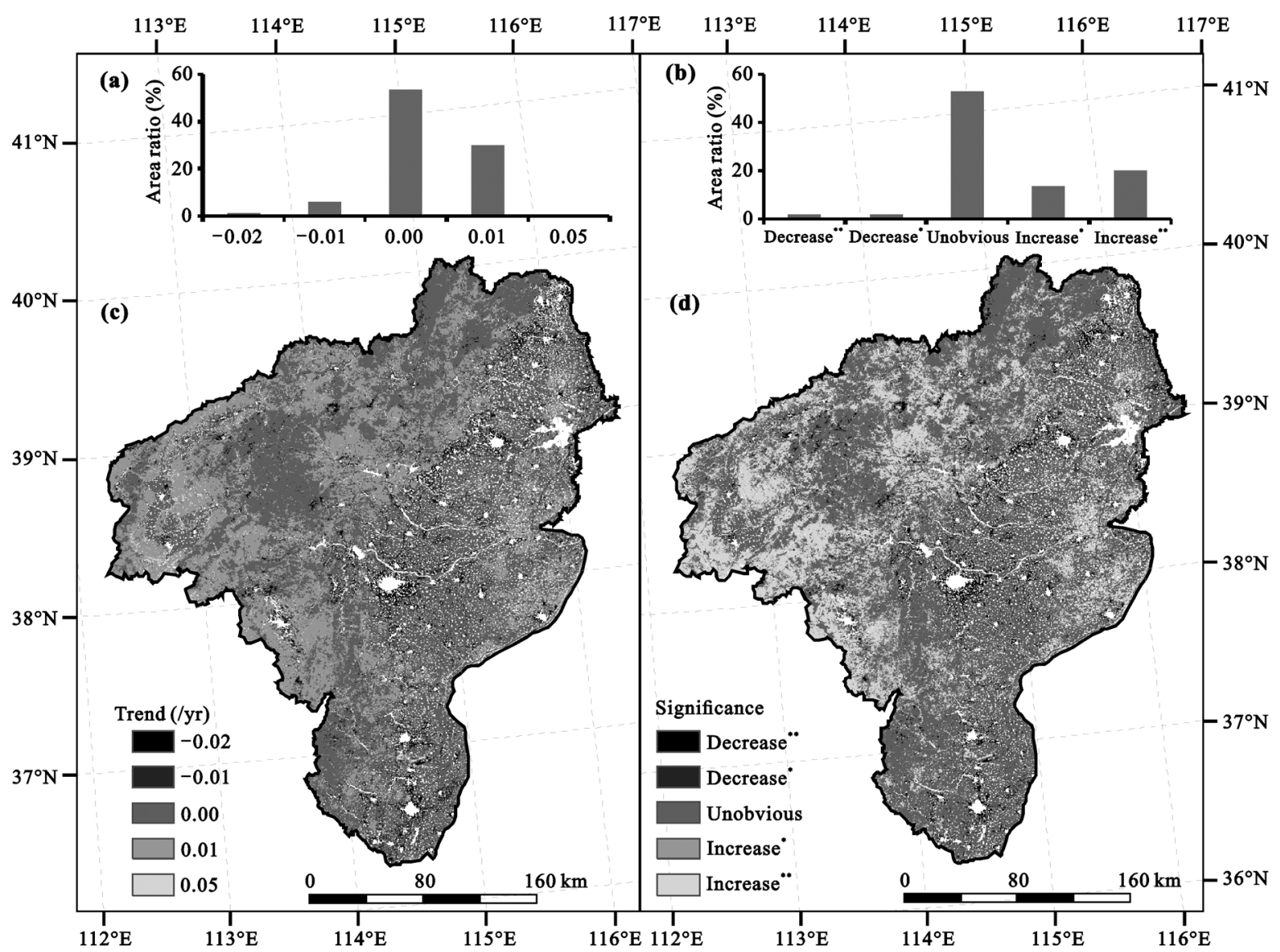

Fig. 4 Linear trend of annual mean NDVI variation (c) and its significance (d) during 2001 and 2012. **: $P<0.01, *$ : $P<0.05$. The area ratio of each value is shown in (a) and (b) 
Table 1 Trend of annual mean NDVI for each land use type

\begin{tabular}{cccccc}
\hline Land use & Forest & Grass & MDL & HDL & PDL \\
\hline Trend (/yr) & $0.0031^{*}$ & $0.0051^{*}$ & $0.0053^{*}$ & $0.0041^{*}$ & 0.0004 \\
\hline
\end{tabular}

Notes: MDL: mountain dry land; HDL: hilly dry land; PDL: plain dry land. * means $P<0.05$

the same as that of the area ratio for the area with significant NDVI trend. It indicated that the variation of vegetation greenness for mountain dry land was the greatest, while vegetation greenness was relatively stable for plain dry land.

\subsubsection{Abrupt change of annual mean NDVI}

The sequential Mann-Kendall test was used to graphically show the forward (UF) and backward (UB) trends of annual mean NDVI during 2001-2012 for forest, grass, mountain dry land and hilly dry land (Fig. 5). Because linear changing trend and UF trend of PDL NDVI are both not significant, so PDL is not analyzed in this section. For grass, mountain dry land and hilly dry land, there were significant response of vegetation greenness to exceptional precipitation during 2001-2012. For these three land use types, the precipitation in 2005-2006 was extremely low and $95 \mathrm{~mm}$ below the maximum value during the study period. However, the precipitation in 2007-2008 increased by $90 \mathrm{~mm}$ compared to that in 2005-2006, and there was
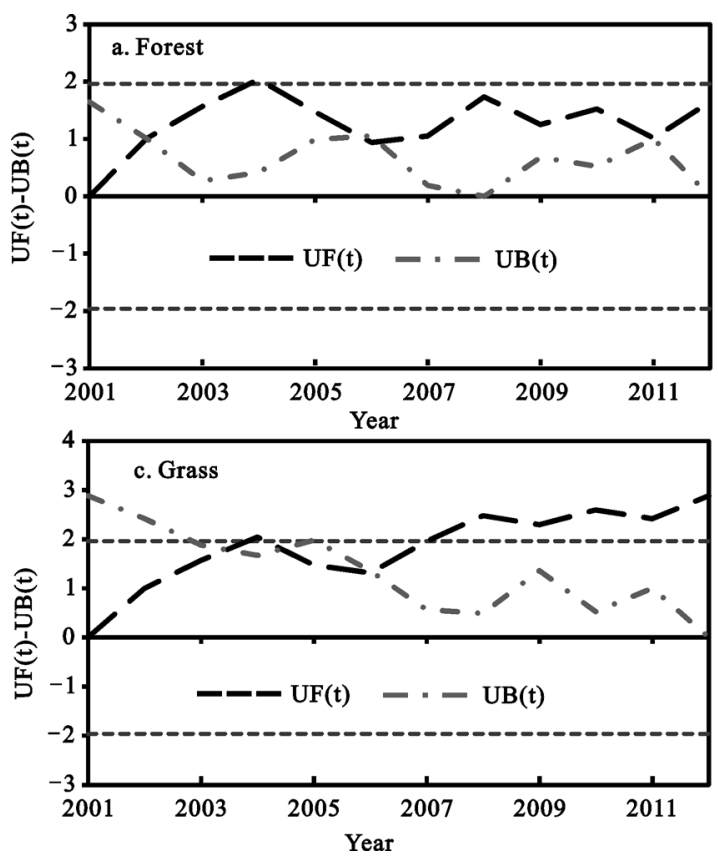

significant NDVI increase in 2008 for grass, mountain dry land and hilly dry land (Fig. 5). For forest, as the lengthy root system could uptake the deep soil water when there was water stress (Eamus et al., 2013), the vegetation response to exceptional precipitation was not significant (Fig. 5). For grass and mountain dry land, NDVI abrupt change occurred in 2006 and 2005, corresponding to the local minimum annual precipitation for each land use type. For grass, annual precipitation in 2006 was $437 \mathrm{~mm}$, which was smaller than that in the former three and latter two years. Moreover, this value was $59 \mathrm{~mm}$ lower than the mean value for the former three years and $96 \mathrm{~mm}$ for the latter two years. For mountain dry land, annual precipitation in 2005 was 428 $\mathrm{mm}$, which was $16 \%$ below the mean value for the former two years and $14 \%$ below that for the latter three years.

\subsubsection{Persistence in NDVI series}

As shown in Fig. 6, Hurst exponent was larger than 0.5 in most area with significant NDVI trend (Fig. 4), which indicated that the NDVI trend in the future will be the same as that during 2001-2012. The area where Hurst exponent was greater than 0.8 , namely the persistence of NDVI variation in the future will be stronger, was mainly with low NDVI, small slope and high elevation. On the contrary, the area with Hurst exponent below 0.5,
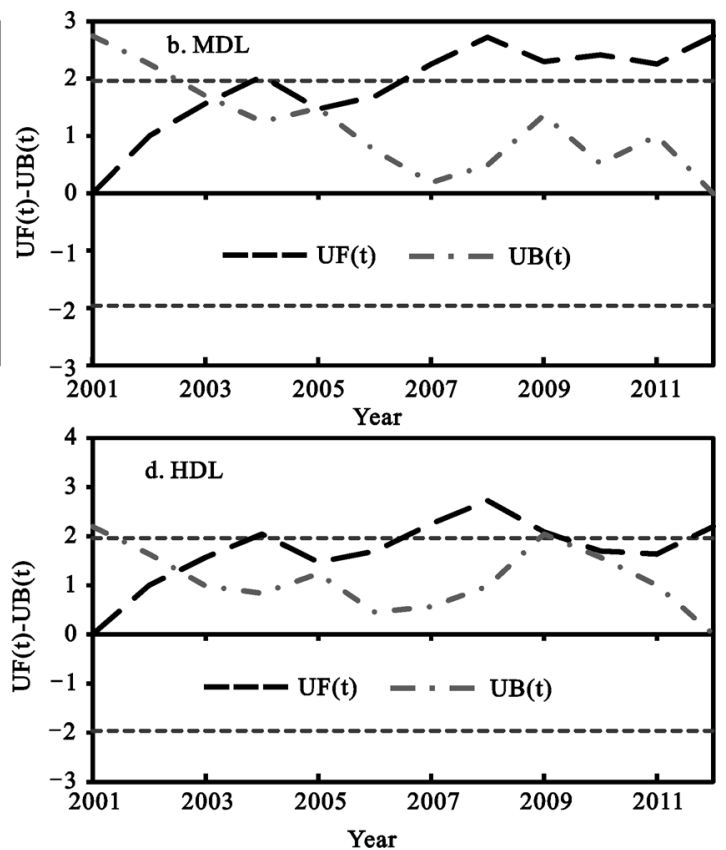

Fig. 5 Sequential Mann-Kendall test of annual mean NDVI with forward-trend UF(t) and backward-trend UB(t) for each land use type. a. Forest; b. MDL; c. Grass; d. HDL. MDL and HDL refer to mountain and hilly dry land, respectively. Gray horizontal lines represent critical values corresponding to the $95 \%$ confidence interval 
namely the variation in the future will be opposite to that at present, was mainly with high NDVI, great slope and low elevation and took up $1 \%$ of the basins. For the land use types with significant NDVI trend (Table 1), Hurst exponent was all greater than 0.5, indicating that NDVI of these land use types will maintain an upward trend in the future. Since mountain dry land and grass NDVI was increasing continuously and significantly in the latter part of the study period, namely during 2008-2012 (as shown in Fig. 5), the increasing persistence for these two types was stronger than that for hilly dry land and forest.

\subsection{Effects of temperature and precipitation on NDVI}

\subsubsection{Spatial characteristics of annual temperature} and precipitation effects

Temperature and precipitation influenced the vegetation growth mainly through the direct effect. As shown in Fig. 7 , in $42 \%$ of the area where the path analysis was effective and NDVI correlated significantly with temperature $(P<0.05)$, the magnitude of the direct effect of temperature was greater than its indirect effect, and in

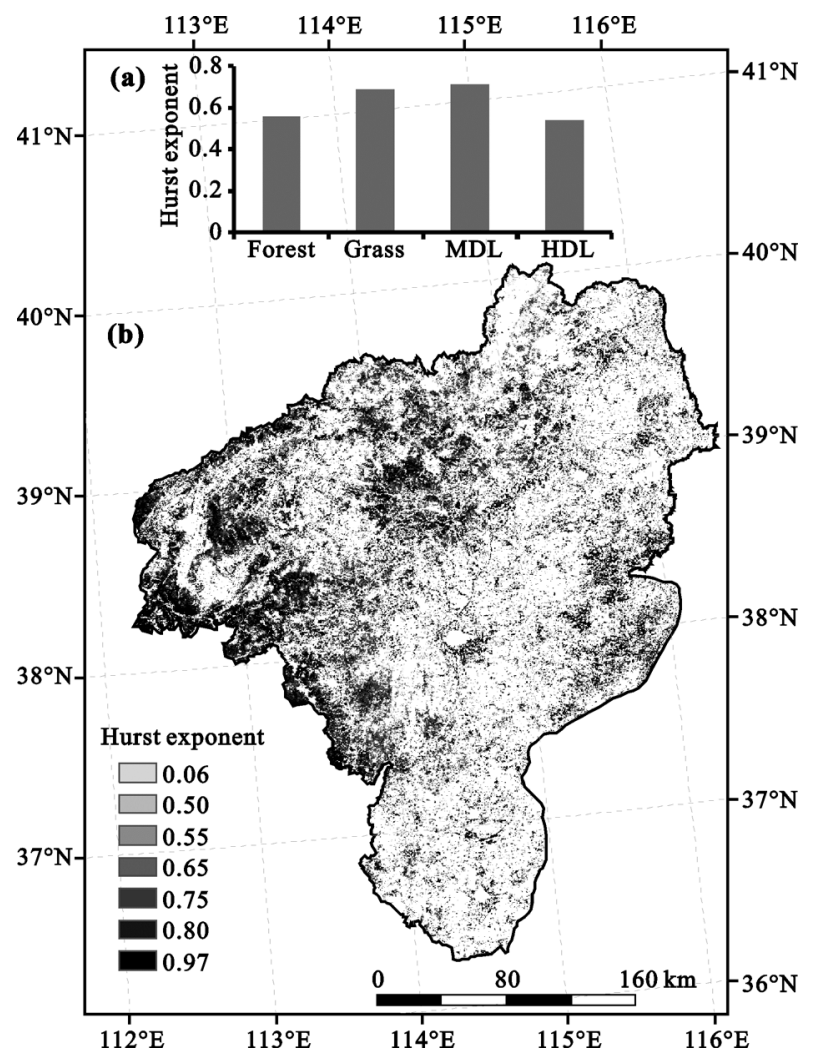

Fig. 6 Hurst exponent $(H)$ of annual mean NDVI for land use types (a) and its spatial distribution (b) during 2001-2012. MDL and HDL refer to mountain and hilly dry land, respectively
$58 \%$ of this area the magnitude of the direct and indirect effects were comparable. It indicated that the direct effect of temperature was generally greater than the indirect one and the impact of temperature was mainly through the direct effect. Similarly, the impact of precipitation on vegetation was also mainly through its direct effect. Further, the direct effects of temperature and precipitation on vegetation growth were opposite. The direct effect of temperature was mostly negative (Fig. $7 a)$, implying annual temperature rise was unfavorable for vegetation growth in the basins. However, most of the direct effect of precipitation was positive (Fig. 7b), indicating annual precipitation increase was beneficial to the vegetation growth, which agreed with the result of $\mathrm{Xu}$ et al. (2014) in this study area.

The combined effect of temperature and precipitation was dominant by the direct effect of precipitation. On the one hand, the spatial pattern of the significant combined effect $(P<0.05)$ was different from that of the direct effect of temperature but similar to that of the direct effect of precipitation. For the area where the direct effect of temperature was significant $(P<0.05)$, this effect was sparse in the whole basins. For the area where the direct effect of precipitation was significant $(P<$
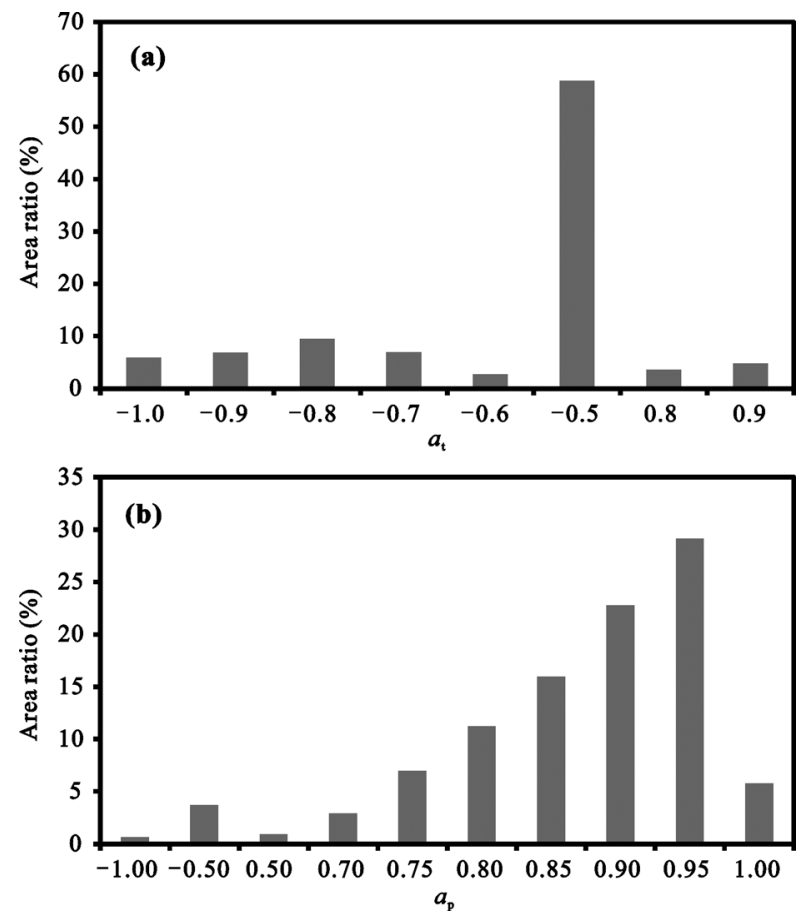

Fig. 7 Area ratios of relative effect of temperature $\alpha_{\mathrm{t}}$ (a) and precipitation $\alpha_{\mathrm{p}}$ (b) in area where path analysis is effective and correlation coefficient between NDVI and temperature (precipitation) is significant 
0.05), the high value was less and sparse in the east, but it was more and dense in the mid-west. On the other hand, the area with significant direct effect of precipitation was greater than that of temperature. The area where the direct effect of precipitation was significant took up $35 \%$ of the basins, while that with significant direct effect of temperature only took up $7 \%$.

Therefore, precipitation was the primary climatic factor that affected the vegetation growth in the Ziya-Daqing basins. This was consistent with the result of Zhao et al. (2010) who analyzed the effects of climate and site conditions on the vegetation distribution among the Taihang Mountains based on Leaf Area Index (LAI).

\subsubsection{Effects of annual temperature and precipitation for each land use type}

As shown in Table 2, for forest, NDVI correlated positively with precipitation but negatively with temperature. It suggested that precipitation increase and temperature decrease would be beneficial to the forest growth, in accordance with the result of Yang et al. (2006) who analyzed the effect of precipitation and temperature on the stem volume in the Taihang Mountains based on the forest inventory data from 712 forest sample plots. Actually, precipitation in April and May in this region was both less than $40 \mathrm{~mm}$. Drought in late spring and early summer always limited the forest growth. Temperature increase might increase evapotranspiration and reduce soil moisture, further limiting the plant growth (Yang et al., 2003). For grass, the correlations between temperature, precipitation and NDVI were similar to those of forest, and NDVI correlated more closely with precipitation than temperature. It indicated that grass growth related more closely to pre- cipitation, which agreed with the result in the central Great Plains of the USA (Paruelo and Lauenroth, 1995; Wang et al., 2001) and Inner Mongolia of China (Chuai et al., 2013). For the two land use types above as well as mountain dry land, hilly dry land and plain dry land in Xinzhou Basin, the direct effect of precipitation was greater than the indirect effect of precipitation, the direct and indirect effects of temperature. This was because the changes in vegetation productivity highly coincided with the variations of soil moisture in Taihang Mountains, and precipitation increase will lead to the increase of soil water (Yang et al., 2003). In fact, for the vegetation among the Taihang Mountains, the soil layer depth is generally less than $50 \mathrm{~cm}$, and the infiltration after a rainstorm may compose $70 \%$ of the soil water (Song et al., 2010).

In terms of plain dry land in the NCP for summer maize growing season, the correlation coefficient between NDVI and precipitation was smaller than that for the plain dry land in Xinzhou Basin. This was because in Xinzhou Basin spring maize was the main crop, and precipitation in the early growth stage of spring maize (May) was smaller than that in the early growth stage of summer maize (June). As a result, NDVI of summer maize was less sensitive to precipitation than spring maize. For winter wheat in the NCP, the correlation between temperature and NDVI was positive, which suggests that temperature rising may lead to the increase of wheat yield. It can be explained that warming mainly occurred before flowing, which leads to earlier and longer reproductive stage (Liu et al., 2010). However, for other vegetation in the basins, NDVI related negatively to temperature. It could be explained that water

Table 2 Effects of annual precipitation and temperature on NDVI for each land use type

\begin{tabular}{cllllllc}
\hline Land use & $r_{\mathrm{p} n d v i}$ & $A_{\mathrm{p}}$ & $A_{\mathrm{pt}}$ & $r_{\mathrm{tndvi}}$ & $A_{\mathrm{t}}$ & $A_{\mathrm{tp}}$ & $R_{t}$ \\
\hline Forest & $0.89^{* *}$ & $0.94^{* *}$ & -0.05 & -0.11 & 0.19 & -0.30 & $0.90^{* *}$ \\
Grass & $0.90^{* *}$ & $0.98^{* *}$ & -0.08 & -0.35 & 0.16 & -0.51 & $0.91^{* *}$ \\
MDL & $0.89^{* *}$ & $0.99^{* *}$ & -0.10 & -0.30 & 0.20 & -0.50 & $0.91^{* *}$ \\
HDL & $0.84^{* *}$ & $0.85^{*}$ & -0.01 & -0.41 & 0.02 & -0.43 & $0.84^{*}$ \\
W-PDL & $0.71^{* *}$ & $0.74^{*}$ & -0.03 & -0.35 & 0.05 & -0.40 & $0.71^{*}$ \\
ncpwheat & 0.55 & 0.53 & 0.02 & 0.33 & 0.29 & 0.04 & 0.62 \\
ncpmaize & 0.33 & 0.31 & 0.02 & -0.20 & -0.05 & -0.15 & 0.34 \\
\hline
\end{tabular}

Notes: $r_{\mathrm{p} n d v i}:$ correlation coefficient between precipitation and NDVI; $A_{\mathrm{p}}$ : direct effect of precipitation; $A_{\mathrm{pt}}$ : indirect effect of precipitation via temperature; $r_{\mathrm{t} n d v i}$ : correlation coefficient between temperature and NDVI; $A_{\mathrm{t}}$ : direct effect of temperature; $A_{\mathrm{tp}}$ : indirect effect of temperature via precipitation; $R_{t}$ : combined effect of temperature and precipitation; MDL: mountain dry land; HDL: hilly dry land; W-PDL: plain dry land in Xinzhou Basin; ncpwheat: plain dry land in the North China Plain for winter wheat growing season; ncpmaize: plain dry land in the North China Plain for summer maize growing season. $* *$ means $P<0.01$ and $*$ means $P<0.05$ 
was the limited factor for vegetation growth in the study area, and higher temperature accelerated the evaporation process, which led to water scarcity and was unfavorable to vegetation growth (Chuai et al., 2013).

For vegetation in the mid-west (forest, grass, mountain dry land, hilly dry land and plain dry land in Xinzhou Basin), the combined effect of temperature and precipitation was significant $(P<0.05)$, while for vegetation in the east (winter wheat and summer maize in the NCP) it was not, as illustrated in Table 2. Moreover, the percentage of the area with significant $(P<0.05)$ combined effect for vegetation in the mid-west was larger than that in the east. In the mid-west, for forest the area with significant combined effect accounted for $36 \%$ of the total area of this land use type, considering that $21 \%$ was from shrub. The area percentage was $47 \%$ for grass $(13 \%, 20 \%$ and $14 \%$ from dense, moderate and sparse grass), $54 \%, 37 \%$ and $28 \%$ for mountain dry land, hilly dry land and plain dry land in Xinzhou Basin respectively. In the east, this ratio for plain dry land was only $8 \%$. It was probably because in the NCP the impact of precipitation and temperature on crop growth was complicated by irrigation (Mo et al., 2009). Therefore, for vegetation in the Taihang Mountains the influence of climatic variations was greater, and in the east the impact of human activity was important, which agreed with the prediction that mountain ecosystems was more sensitive to climate change (Anderson and Goulden, 2011).

\subsubsection{Spatial distribution of primary effect}

Climate is the important factor that impacts the vegetation growth, but the influence of human activity should not be neglected. In this study, we examined the area where the vegetation growth was dominated by human activity and the direct and indirect effects of temperature and precipitation (Table 3).
As shown in Fig. 8, the vegetation growth was dominated by human activity in $61 \%$ of the basins (except for built-up land and water area). The area with the direct effect of precipitation as the primary effect took up $23 \%$ of the basins, and that with the direct effects of temperature and precipitation as the primary effects accounted for $5 \%$. For the whole basins, the area where the vegetation growth was dominated by the direct effect of temperature and indirect effect of temperature or precipitation was about $1 \%$. The ratios of area impacted by human activity and climatic variations agreed with other researches. According to the result in Haihe River Basin (Wang et al., 2014) based on partial and multiple correlation coefficients, the area impacted collaboratively by temperature and precipitation took up $10 \%$, that only by precipitation is $21 \%$, and that by human activity accounts for $68 \%$.

In fact, in the area where vegetation growth was dominated by human activity, NDVI fluctuation (Fig. 2) and change trend was smaller, with insignificant variations (Fig. 4). This was because this area was mainly composed of plain dry land with water supply and irrigation facilities. In the area where precipitation or temperature dominated the vegetation growth, NDVI fluctuation (Fig. 2) and change trend was greater, with significant variations (Fig. 4). It can be explained that this kind of area was mainly composed of grass and forest, which was sensitive to climatic variations. For these two land use types, more than $90 \%$ of the NDVI variation could be explained by temperature and precipitation (Table 2). Moreover, for forest and grass in Taihang Mountains annual precipitation increase directly caused the NDVI increase. In fact, compared to the mean annual precipitation during 2001-2006 (455 mm), the value during 2007-2012 (515 mm) increased by $13 \%$.

Table 3 Rules for identifying impact of climatic variations and human activity

\begin{tabular}{|c|c|c|c|c|c|c|}
\hline \multirow{2}{*}{ Effect } & \multirow{2}{*}{ Human activity } & \multicolumn{5}{|c|}{ Climatic variation } \\
\hline & & $A_{\mathrm{p}}$ and $A_{\mathrm{t}}$ & $A_{\mathrm{p}}$ & $A_{\mathrm{t}}$ & $A_{\text {tp }}$ & $A_{\mathrm{pt}}$ \\
\hline$R_{t}$ & $P>0.05$ & $P<0.05$ & $P<0.05$ & $P<0.05$ & $P<0.05$ & $P<0.05$ \\
\hline$A_{\mathrm{p}}$ & & $P<0.05$ & $P<0.05$ & $P>0.05$ & $P>0.05$ & $P>0.05$ \\
\hline$A_{\mathrm{t}}$ & & $P<0.05$ & $P>0.05$ & $P<0.05$ & $P>0.05$ & $P>0.05$ \\
\hline$A_{\mathrm{pt}}$ & & & & & $\left|A_{\mathrm{pt}}\right|<\left|A_{\mathrm{tp}}\right|$ & \\
\hline$A_{\mathrm{tp}}$ & & & & & & $\left|A_{\mathrm{pt}}\right|>\left|A_{\mathrm{tp}}\right|$ \\
\hline
\end{tabular}

Notes: $A_{\mathrm{p}}$ : direct effect of precipitation; $A_{\mathrm{t}}$ : direct effect of temperature; $A_{\mathrm{tp}}$ : indirect effect of temperature via precipitation; $A_{\mathrm{pt}}$ : indirect effect of precipitation via temperature; $R_{t}$ : combined effect of temperature and precipitation 


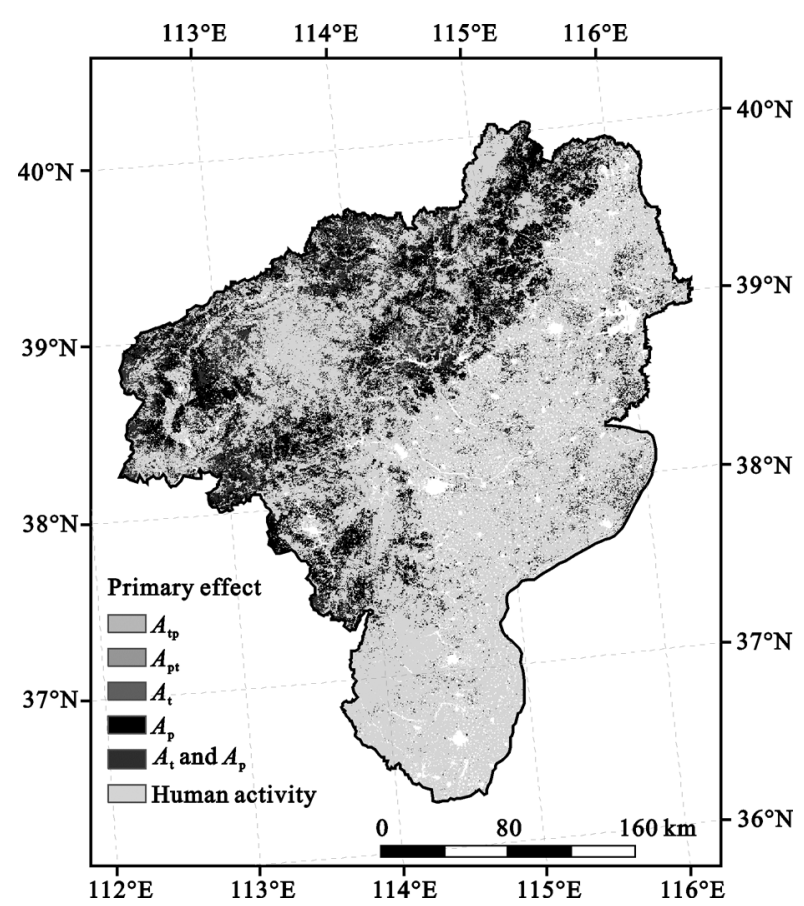

Fig. 8 Spatial distribution of the effect dominated by climatic factors and human activity. $A_{\mathrm{tp}}$ : indirect effect of temperature via precipitation; $A_{\mathrm{pt}}$ : indirect effect of precipitation via temperature; $A_{\mathrm{t}}$ : direct effect of temperature; $A_{\mathrm{p}}$ : direct effect of precipitation

Particularly, the sum precipitation in July, August and September increased by $50 \mathrm{~mm}$, which took up $83 \%$ of the annual precipitation increase. It might be inferred that precipitation increase during July, August and September led to the NDVI increase in Taihang Mountains.

Although vegetation growth in the Taihang Mountains was dominated by climatic variations, it should be noticed that the afforested area of the large-scale vegetation restoration project 'Greening Project of Taihang Mountains' was $8510 \mathrm{~km}^{2}$ during 2001-2009 (Zeng et al., 2010), which might have been partly responsible for the greenness increase there.

\subsubsection{Relationship between monthly temperature, precipitation and NDVI}

The impact of temperature and precipitation on NDVI varies with growth stages (Piao et al., 2006). In order to identify this difference at the monthly timescale, the correlation coefficients $(R)$ between monthly NDVI and these two climatic variables in the current and preceding 1-, 2- and 3-month were calculated, as shown in Table 4.

For all land use types, NDVI in April correlated positively with temperature in current month, while NDVI in June, July and August correlated negatively with temperature in current month. It suggested that warming will promote vegetation growth in the early growth stage but inhibit in the middle stage. At the beginning of the growing season temperature increase can reduce frost damage, thaw out the frozen soil, promote plant photosynthesis, and thereby boosted vegetation growth (Welp et al., 2007; Guo et al., 2014). In the middle of the growing season, warming can inhibit photosynthesis directly or through water stress, and is unfavorable to vegetation growth (Wang et al., 2003). Compared the correlation coefficient between NDVI and temperature in the current month with that between NDVI and temperature of 1-, 2-, 3-month preceding, it was found that September NDVI of forest, August NDVI of plain dry land in Xinzhou Basin, August (September) NDVI of plain dry land in the NCP responded to temperature with 2-, 1- and 1-month lag-time significantly $(P<0.05,|R| \geq$ 0.58 ). For plain dry land in the NCP, there was a significant negative correlation between August (September) NDVI and July (August) temperature, which suggested that temperature rising in summer was not beneficial for maize and might lead to productivity decline (Tao et al., 2006).

For all land use types, monthly NDVI correlated positively with precipitation in the current month, except August NDVI of plain dry land in the NCP. For plain dry land in the NCP, August precipitation is usually sufficient for summer maize growth and excess rainfall may lead to water logging $(\mathrm{He}, 2012)$, which is not good for vegetation growth. Most correlations between NDVI and precipitation of 1-, 2-, 3-month preceding were positive, which indicated that precipitation increase in previous period was generally favorable to vegetation growth in the basins. Compared the correlation coefficient between NDVI and precipitation in the current month with that between NDVI and precipitation of 1-, 2-, 3-month preceding, it showed that June NDVI of mountain dry land responded to precipitation with 3-month lag-time significantly $(P<0.05,|R| \geq$ 0.58 ), May and September NDVI of hilly dry land with 1-month, May and July NDVI of plain dry land in Xinzhou Basin with 1-2 month(s), and July and August NDVI of plain dry land in the NCP with 1-2 month(s).

\subsection{Phenology response to temperature and pre- cipitation variations}

The onset date of greenness for natural vegetation ranged from the 120th to 132th day of a year during 
Table 4 Correlation coefficients between monthly temperature, precipitation and NDVI for each land use type

\begin{tabular}{|c|c|c|c|c|c|c|c|c|c|c|c|c|c|}
\hline \multirow{2}{*}{ Land use } & \multirow{2}{*}{ No. } & \multicolumn{6}{|c|}{ Temperature } & \multicolumn{6}{|c|}{ Precipitation } \\
\hline & & Apr. & May & Jun. & Jul. & Aug. & Sept. & Apr. & May & Jun. & Jul. & Aug. & Sept. \\
\hline \multirow[t]{4}{*}{ Forest } & 0 & $0.58^{*}$ & -0.03 & -0.30 & -0.17 & -0.01 & 0.02 & 0.54 & 0.17 & 0.11 & 0.34 & 0.23 & $0.69^{*}$ \\
\hline & 1 & -0.23 & 0.17 & -0.05 & -0.24 & -0.21 & 0.31 & 0.18 & 0.48 & 0.44 & 0.40 & 0.54 & 0.46 \\
\hline & 2 & -0.40 & -0.48 & -0.19 & -0.15 & -0.02 & $0.59^{*}$ & -0.02 & 0.24 & 0.30 & 0.48 & 0.20 & -0.08 \\
\hline & 3 & -0.39 & -0.35 & -0.24 & 0.14 & -0.34 & 0.29 & -0.09 & 0.03 & 0.56 & 0.04 & 0.47 & -0.22 \\
\hline \multirow[t]{4}{*}{ Grass } & 0 & 0.42 & -0.08 & -0.45 & -0.29 & -0.21 & -0.20 & $0.59^{*}$ & 0.27 & 0.33 & 0.37 & 0.33 & $0.64^{*}$ \\
\hline & 1 & -0.26 & 0.06 & -0.13 & -0.30 & -0.26 & 0.05 & 0.36 & 0.55 & 0.32 & 0.45 & 0.48 & $0.60^{*}$ \\
\hline & 2 & -0.37 & -0.44 & -0.15 & -0.19 & -0.10 & 0.44 & -0.11 & 0.34 & 0.36 & 0.45 & 0.15 & -0.11 \\
\hline & 3 & -0.39 & -0.38 & -0.13 & 0.19 & -0.43 & 0.14 & -0.13 & -0.12 & 0.57 & 0.01 & 0.56 & -0.31 \\
\hline \multirow[t]{4}{*}{ MDL } & 0 & 0.38 & -0.02 & -0.42 & -0.30 & -0.24 & -0.23 & 0.49 & 0.29 & 0.37 & 0.41 & 0.33 & 0.55 \\
\hline & 1 & -0.36 & 0.06 & -0.13 & -0.27 & -0.30 & 0.05 & 0.41 & 0.45 & 0.36 & 0.43 & 0.50 & $0.58^{*}$ \\
\hline & 2 & -0.38 & -0.53 & -0.16 & -0.23 & -0.15 & 0.42 & 0.00 & 0.43 & 0.33 & 0.54 & 0.16 & -0.04 \\
\hline & 3 & -0.44 & -0.41 & -0.13 & 0.18 & -0.45 & 0.18 & -0.15 & -0.04 & $0.58^{*}$ & -0.04 & 0.54 & -0.30 \\
\hline \multirow[t]{4}{*}{ HDL } & 0 & $0.61^{*}$ & 0.03 & $-0.67^{*}$ & $-0.63^{*}$ & -0.47 & -0.34 & $0.60^{*}$ & 0.03 & $0.59^{*}$ & 0.35 & 0.31 & 0.35 \\
\hline & 1 & 0.10 & 0.14 & -0.17 & -0.45 & -0.42 & -0.34 & 0.17 & $0.74^{*}$ & 0.20 & 0.56 & 0.46 & $0.74^{*}$ \\
\hline & 2 & -0.10 & -0.33 & 0.09 & -0.20 & -0.23 & 0.32 & -0.33 & 0.41 & 0.52 & 0.46 & 0.18 & 0.03 \\
\hline & 3 & -0.06 & -0.32 & 0.10 & 0.36 & -0.43 & 0.17 & 0.08 & -0.34 & 0.47 & 0.14 & 0.41 & $-0.62^{*}$ \\
\hline \multirow[t]{4}{*}{ W-PDL } & 0 & $0.68^{*}$ & 0.05 & -0.51 & $-0.71^{*}$ & -0.41 & -0.08 & 0.35 & 0.27 & 0.54 & 0.37 & 0.12 & 0.41 \\
\hline & 1 & 0.47 & 0.19 & -0.21 & -0.48 & $-0.73^{*}$ & -0.46 & 0.02 & 0.44 & 0.28 & $0.65^{*}$ & 0.49 & 0.56 \\
\hline & 2 & 0.13 & -0.06 & 0.01 & -0.20 & -0.43 & -0.09 & -0.23 & $0.58^{*}$ & 0.34 & 0.43 & 0.39 & -0.05 \\
\hline & 3 & 0.23 & -0.04 & -0.02 & 0.37 & -0.55 & -0.34 & 0.20 & -0.16 & 0.48 & 0.08 & 0.51 & -0.38 \\
\hline \multirow[t]{4}{*}{ ncpPDL } & 0 & $0.71^{*}$ & -0.07 & -0.15 & -0.55 & -0.05 & -0.39 & 0.36 & 0.23 & 0.14 & 0.05 & -0.44 & $0.74^{*}$ \\
\hline & 1 & $0.66^{*}$ & -0.23 & 0.06 & -0.09 & $-0.63^{*}$ & $-0.60^{*}$ & -0.03 & 0.29 & 0.32 & $0.61^{*}$ & 0.37 & 0.39 \\
\hline & 2 & 0.26 & -0.17 & 0.04 & 0.06 & -0.39 & 0.07 & -0.45 & 0.30 & -0.21 & 0.43 & $0.66^{*}$ & 0.35 \\
\hline & 3 & 0.41 & -0.19 & -0.02 & $0.64^{*}$ & -0.26 & -0.52 & 0.01 & -0.47 & 0.55 & -0.12 & 0.42 & -0.27 \\
\hline
\end{tabular}

Notes: these two climatic variables are 0-, 1-, 2- and 3-month before monthly NDVI. MDL: mountain dry land; HDL: hilly dry land; W-PDL: plain dry land in Xinzhou Basin; ncpPDL: plain dry land in the North China Plain. * means $P<0.05$

2001-2012, and the average was about the 124th day. According to the ensemble result of five methods for North China (Cong et al., 2013), the onset date of natural vegetation was about the 128th day, which was later than that in the present work. It was probably because the latitude of the present study area was lower. The cessation date of greenness ranged from the 276th to 288th day (early and middle October), which was earlier than the result for Beijing deciduous broadleaf forest (late October) reported by $\mathrm{Xu}$ (2012). It was due to the different methods and vegetation types.

The relationship between the onset date and temperature in the current and 1-preceding month was investigated. It was found that the onset date correlated more closely with temperature in 1-preceding month (April) than in the current month (May). The correlation coefficient between the onset date and April temperature was negative. The onset date will approximately advance by 2 days if April temperature increases by $1{ }^{\circ} \mathrm{C}$ (Fig. 9). According to present studies, the sensitivity of the onset date to April temperature was $-3.2 \mathrm{~d} /{ }^{\circ} \mathrm{C}$ for Beijing deciduous broadleaf forest (Xu, 2012). To spring temperature, it was $-2.5 \mathrm{~d} /{ }^{\circ} \mathrm{C}$ for European (Menzel et al., 2006) and China (Wang et al., 2015b) temperate vegetation, while $-3.7 \mathrm{~d} /{ }^{\circ} \mathrm{C}$ for China subtropical vegetation (Wang et al., 2015b). To temperature in the preceding 60 days the sensitivity was -2.1 and $-1.9 \mathrm{~d} /{ }^{\circ} \mathrm{C}$ for North China deciduous broadleaf and grass (Cong et al., 2013). Obviously, the result in the present work was close to those above, while due to different study areas and previous periods for temperature there was tiny difference. Further, soil water condition may impact the response of onset date to April temperature. For example, 


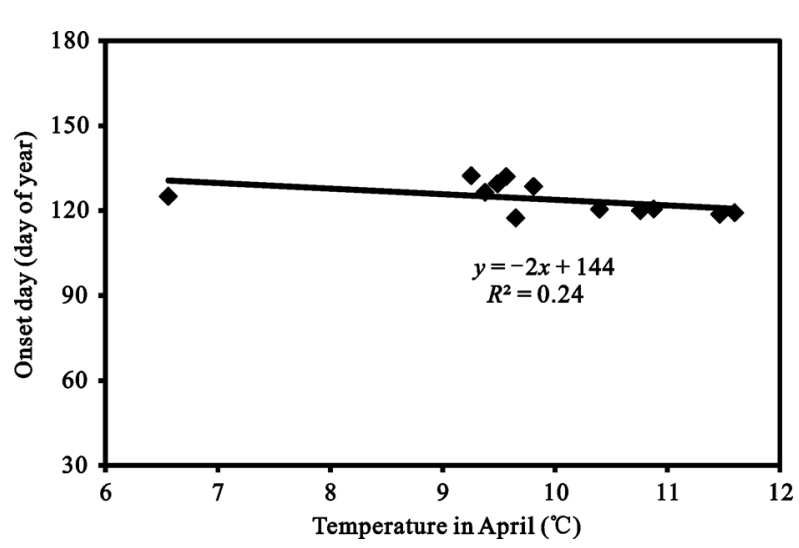

Fig. 9 Sensitivity of onset date of greenness to mean temperature in April for natural vegetation

in 2003, April temperature was slightly lower than the multi-year average, but the onset day did not delay. This was because April temperature in that year was still greater than $5^{\circ} \mathrm{C}$ and the heat for vegetation growth could be satisfied (Kaduk and Heimann, 1996). April precipitation in 2003 was greater than the multi-year average, leading to more soil water and the early onset (Yu et al., 2003).

The cessation day of natural vegetation correlated weakly with September temperature, but significantly with September precipitation $(P<0.05)$. It is probably because the relationship between the cessation day and temperature is relatively uncertain (Menzel, 2003; Wang et al., 2015a). However, the cessation day will delay if the precipitation increases.

\section{Conclusions}

Based on MODIS NDVI, temperature and precipitation data during 2001-2012, the vegetation dynamics and its response to climatic variations in the Ziya-Daqing basins was investigated in this study.

The inter-annual NDVI variation varied with land use types. The vegetation productivity had small inter-annual fluctuation and showed insignificant trend in most plain dry land. Due to urbanization (5\% of plain dry land changed into built-up land during 2001-2012), the vegetation productivity showed significant downward trend in plain dry land around the city. For forest, grass and dry land among Taihang Mountains, the significant upward trend was found in the past 12 years and vegetation productivity will continue to increase in the future.

Even though the vegetation growth was dominated by human activity in $61 \%$ of the basins, for the area where NDVI changed significantly, the inter-annual NDVI variation was primarily determined by the effect of precipitation and this effect was not regulated by temperature. For the land use types with significant NDVI trend, the direct effect of precipitation was greater than the direct effect of temperature and indirect effects of temperature and precipitation, which dominated the combined effect of precipitation and temperature.

Precipitation increase (especially in July, August and September) was favorable to greenness enhancement. Summer temperature rising showed negative effect on plant productivity enhancement, but temperature rise in April was beneficial for the vegetation growth. The onset date of greenness for natural vegetation will advance by 2 days if April temperature increases by $1{ }^{\circ} \mathrm{C}$.

There was a significant lag-time effect of precipitation or temperature on monthly NDVI for all land use types except grass. The lag-time effect of temperature was significant for forest. This effect of precipitation was significant for hilly and mountain dry land. For plain dry land in the NCP and Xinzhou Basin, the lag-time effects of both temperature and precipitation were significant.

\section{References}

Anderson R G, Goulden M L, 2011. Relationships between climate, vegetation, and energy exchange across a montane gradient. Journal of Geophysical Research, 116(G01026): 1-16. doi: 10.1029/2010JG001476

Cao S, Chen L, Shankman D et al., 2011. Excessive reliance on afforestation in China's arid and semi-arid regions: lessons in ecological restoration. Earth-Science Reviews, 104(4): 240245. doi: 10.1016/j.earscirev.2010.11.002

Chamaille-Jammes S, Fritz H, Murindagomo F, 2006. Spatial patterns of the NDVI-rainfall relationship at the seasonal and interannual time scales in an African savanna. International Journal of Remote Sensing, 27(23): 5185-5200. doi: 10.1080/ 01431160600702392

Chen F, Shen Y, Hu Q et al., 2011. Responses of NDVI to climate change in the Hai Basin. Journal of Remote Sensing, 15(2): 401-414.

Chuai X W, Huang X J, Wang W J et al., 2013. NDVI, temperature and precipitation changes and their relationships with different vegetation types during 1998-2007 in Inner Mongolia, China. International Journal of Climatology, 33(7): 16961706. doi: $10.1002 /$ joc. 3543

Cong N, Wang T, Nan H et al., 2013. Changes in satellite-derived spring vegetation green-up date and its linkage to climate in 
China from 1982 to 2010: a multimethod analysis. Global Change Biology, 19(3): 881-891. doi: 10.1111/gcb.12077

Cui Y P, Liu J Y, Hu Y F et al., 2012. An analysis of temporal evolution of NDVI in various vegetation-climate regions in Inner Mongolia, China. Procedia Environmental Sciences, 13: 1989-1996. doi: 10.1016/j.proenv.2012.01.192

Eamus D, Boulain N, Cleverly J et al., 2013. Global change-type drought-induced tree mortality: vapor pressure deficit is more important than temperature per se in causing decline in tree health. Ecology and Evolution, 3(8): 2711-2729. doi: 10.1002/ ece3.664

Fang Ping, He Yan, 2003. Experiment Design and Statistics. Hangzhou: Zhejiang University Press. (in Chinese)

Fensholt R, Langanke T, Rasmussen K et al., 2012. Greenness in semi-arid areas across the globe 1981-2007: an Earth Observing Satellite based analysis of trends and drivers. Remote Sensing of Environment, 121: 144-158. doi: 10.1016/j.rse. 2012.01.017

Guo L, Wu S, Zhao D et al., 2014. NDVI-based vegetation change in Inner Mongolia from 1982 to 2006 and its relationship to climate at the biome scale. Advances in Meteorology, 2014: 1-12. doi: 10.1155/2014/692068

Gurgel H C, Ferreira N J, 2003. Annual and interannual variability of NDVI in Brazil and its connections with climate. International Journal of Remote Sensing, 24(18): 3595-3609. doi: 10.1080/0143116021000053788

Gutman G, Ignatov A, 1998. The derivation of the green vegetation fraction from NOAA/AVHRR data for use in numerical weather prediction models. International Journal of Remote Sensing, 19(8): 1533-1543. doi: 10.1080/014311698215333

Hao Jingwen, 2010. Comprehensive Evaluation and Prediction of Hebei Urbanization. Baoding: Hebei University. (in Chinese)

He Qijin, 2012. Study on the Relationships between Maize Cultivation Distribution in China and Climate. Beijing: Chinese Academy of Meteorological Sciences and Nanjing University of Information Science and Technology. (in Chinese)

Hurst H, 1951. Long term storage capacity of reservoirs. Transactions of the American Society of Civil Engineers, 6: 770 799.

Jedrzejek B, Drees B, Daniels F J A et al., 2013. Vegetation pattern of mountains in West Greenland: a baseline for long-term surveillance of global warming impacts. Plant Ecology and Diversity, 6(3-4): 405-422. doi: 10.1080/17550874.2013.802049

Kaduk J, Heimann M, 1996. A prognostic phenology scheme for global terrestrial carbon cycle models. Climate Research, 6(1): 1-19. doi: 10.3354/cr006001

Kawabata A, Ichii K, Yamaguchi Y, 2001. Global monitoring of interannual changes in vegetation activities using NDVI and its relationships to temperature and precipitation. International Journal of Remote Sensing, 22(7): 1377-1382. doi: 10.1080/ 01431160119381

Kerr J T, Ostrovsky M, 2003. From space to species: ecological applications for remote sensing. Trends in Ecology and Evolution, 18(6): 299-305. doi: 10.1016/s0169-5347(03)00071-5

Kinyanjui M J, 2011. NDVI-based vegetation monitoring in Mau forest complex, Kenya. African Journal of Ecology, 49(2): 165-174. doi: 10.1111/j.1365-2028.2010.01251.x

Li S, Lyu S, Gao Y et al., 2015. The change of climate and terrestrial carbon cycle over Tibetan Plateau in CMIP5 models. International Journal of Climatology, 35(14): 4359-4369. doi: 10.1002/joc.4293

Lin Zhonghui, Mo Xingguo, Li Hongxuan et al., 2002. Comparison of three spatial interpolation methods for climate variables in China. Acta Geographica Sinica, 57(1): 47-56. (in Chinese)

Liu Y, Wang E, Yang X et al., 2010. Contributions of climatic and crop varietal changes to crop production in the North China Plain, since 1980s. Global Change Biology, 16(8): 2287-2299. doi: 10.1111/j.1365-2486.2009.02077.x

Matthews H D, Weaver A J, Meissner K J et al., 2004. Natural and anthropogenic climate change: incorporating historical land cover change, vegetation dynamics and the global carbon cycle. Climate Dynamics, 22(5). doi: 10.1007/s00382-0040392-2

Meng M, Ni J, Zong M, 2011. Impacts of changes in climate variability on regional vegetation in China: NDVI-based analysis from 1982 to 2000. Ecological Research, 26(2): 421-428. doi: 10.1007/s11284-011-0801-z

Menzel A, 2003. Plant phenological anomalies in Germany and their relation to air temperature and NAO. Climatic Change, 57(3): 243-263. doi: 10.1023/A:1022880418362

Menzel A, Fabian P, 1999. Growing season extended in Europe. Nature, 397(6721): 659-659.

Menzel A, Sparks T H, Estrella N et al., 2006. European phenological response to climate change matches the warming pattern. Global Change Biology, 12(10): 1969-1976. doi: 10. 1111/j.1365-2486.2006.01193.x

Mo X, Liu S, Lin Z et al., 2009. Regional crop yield, water consumption and water use efficiency and their responses to climate change in the North China Plain. Agriculture, Ecosystems and Environment, 134(1-2): 67-78. doi: 10.1016/j.agee.2009. 05.017

Montaldo N, Rondena R, Albertson J D et al., 2005. Parsimonious modeling of vegetation dynamics for ecohydrologic studies of water-limited ecosystems. Water Resources Research, 41: W10416. doi: 10.1029/2005WR004094

Montanari A, Taqqu M S, Teverovsky V, 1999. Estimating longrange dependence in the presence of periodicity: an empirical study. Mathematical and Computer Modelling, 29(10-12): 217-228. doi: 10.1016/S0895-7177(99)00104-1

Mu Shaojie, Li Jianlong, Chen Yizhao, 2012. Spatial differences of variations of vegetation coverage in Inner Mongolia during 2001-2010. Acta Geographica Sinica, 67(9): 1255-1268. (in Chinese)

Myneni R B, Tucker C J, Asrar G et al., 1998. Interannual variations in satellite-sensed vegetation index data from 1981 to 1991. Journal of Geophysical Research: Atmospheres, 103 (D6): 6145-6160. doi: 10.1029/97JD03603

Olsson L, Eklundh L, Ardö J, 2005. A recent greening of the Sahel-trends, patterns and potential causes. Journal of Arid Environments, 63(3): 556-566. doi: 10.1016/j.jaridenv.2005.03. 
008

Paruelo J M, Lauenroth W K, 1995. Regional patterns of normalized difference vegetation index in North-American shrublands and grasslands. Ecology, 76(6): 1888-1898. doi: 10. 2307/1940721

Piao S, Mohammat A, Fang J et al., 2006. NDVI-based increase in growth of temperate grasslands and its responses to climate changes in China. Global Environmental Change, 16(4): 340-348. doi: 10.1016/j.gloenvcha.2006.02.002

Reed B C, Brown J F, Vanderzee D et al., 1994. Measuring phenological variability from satellite imagery. Journal of Vegetation Science, 5(5): 703-714. doi: 10.2307/3235884

Revadekar J V, Tiwari Y K, Kumar K R, 2012. Impact of climate variability on NDVI over the Indian region during 1981-2010. International Journal of Remote Sensing, 33(22): 7132-7150. doi: 10.1080/01431161.2012.697642

Sánchez G M A, Trinidad S J E, García P J, 2008. Some comments on Hurst exponent and the long memory processes on capital markets. Physica A: Statistical Mechanics and its Applications, 387(22): 5543-5551. doi: 10. 1016/j.physa.2008. 05.053

Savitzky A, Golay M J E, 1964. Smoothing and differentiation of data by simplified least squares procedures. Analytical chemistry, 36(8): 1627-1639. doi: 10.1021/ac60214a047

Schwartz M D, Reed B C, White M A, 2002. Assessing satellite-derived start-of-season measures in the conterminous USA. International Journal of Climatology, 22(14): 17931805. doi: 10.1002/joc.819

Shen M, Tang Y, Chen J et al., 2011. Influences of temperature and precipitation before the growing season on spring phenology in grasslands of the central and eastern Qinghai-Tibetan Plateau. Agricultural and Forest Meteorology, 151(12): 1711-1722. doi: 10.1016/j. agrformet.2011.07.003

Sneyers R, 1975. Sur l'analyse statistique des séries d'observations. WMO Tech Note. (in French)

Song X, Wang P, Yu J et al., 2010. Relationships between precipitation, soil water and groundwater at Chongling basin with the typical vegetation cover in the Taihang mountainous region, China. Environmental Earth Sciences, 62(4): 787-796. doi: 10.1007/s12665-010-0566-7

Sun Long, Guo Qingxi, Zheng Wenchao et al., 2005. The path analysis on NDVI of typical vegetations and climate factors in North-South Transect of Eastern China. Journal of Northeast Forestry University, 33(5): 59-61. (in Chinese)

Tao F, Yokozawa M, Xu Y et al., 2006. Climate changes and trends in phenology and yields of field crops in China, 1981-2000. Agricultural and Forest Meteorology, 138(1-4): 82-92. doi: 10.1016/j.agrformet.2006.03.014

Taqqu M S, Teverovsky V, Willinger W, 1995. Estimators for long-range dependence: an empirical study. Fractals, 03(04): 785-798. doi: 10.1142/S0218348X95000692

Tomsett A C, Toumi R, 2001. Annual persistence in observed and modelled UK precipitation. Geophysical Research Letters, 28(20): 3891-3894. doi: 10.1029/2001g1013337

Wang C, Cao R, Chen J et al., 2015a. Temperature sensitivity of spring vegetation phenology correlates to within-spring warming speed over the Northern Hemisphere. Ecological Indicators, 50: 62-68. doi: 10.1016/j.ecolind.2014.11.004

Wang H, Dai J, Zheng J et al., 2015b. Temperature sensitivity of plant phenology in temperate and subtropical regions of China from 1850 to 2009. International Journal of Climatology, 35: 913-922. doi: 10.1002/joc.4026

Wang J, Price K P, Rich P M, 2001. Spatial patterns of NDVI in response to precipitation and temperature in the central Great Plains. International Journal of Remote Sensing, 22(18): 3827-3844. doi: 10.1080/01431160010007033

Wang J, Rich P M, Price K P, 2003. Temporal responses of NDVI to precipitation and temperature in the central Great Plains, USA. International Journal of Remote Sensing, 24(11): 23452364. doi: 10.1080/01431160210154812

Wang Yongcai, Sun Yanling, Wang Zhongliang, 2014. Spatial-temporal changes in vegetation cover and climatic factor drivers of variations in the Haihe River Basin 1998-2011. Resources Science, 36(3): 594-602. (in Chinese)

Welp L R, Randerson J T, Liu H P, 2007. The sensitivity of carbon fluxes to spring warming and summer drought depends on plant functional type in boreal forest ecosystems. Agricultural and Forest Meteorology, 147(3-4): 172-185. doi: 10.1016/j. agrformet.2007.07.010

White M A, Thornton P E, Running S W, 1997. A continental phenology model for monitoring vegetation responses to interannual climatic variability. Global Biogeochemical Cycles, 11(2): 217-34. doi: 10.1029/97gb00330

Wylie B K, Boyte S P, Major D J, 2012. Ecosystem performance monitoring of rangelands by integrating modeling and remote sensing. Rangeland Ecology and Management, 65(3): 241252. doi: 10.2111/rem-d-11-00058.1

$\mathrm{Xu}$ G, Zhang $\mathrm{H}$, Chen B et al., 2014. Changes in vegetation growth dynamics and relations with climate over China's landmass from 1982 to 2011. Remote Sensing, 6(4): 32633283. doi: 10.3390/rs6043263

$\mathrm{Xu} \mathrm{Ke}, 2012$. Study on Growing Season and Analysis of Its Influence Factors in Beijing Based on MODIS Data. Beijing: Beijing Forest University. (in Chinese)

$\mathrm{Xu}$ Weixin, Liu Xiaodong, 2007. Response of vegetation in the Qinghai-Tibet Plateau to global warming. Chinese Geographical Science, 17(2): 151-159. doi: 10.1007/s11769-0070151-5

Yang L, Wylie B K, Tieszen L L et al., 1998. An analysis of relationships among climate forcing and time-integrated NDVI of grasslands over the U.S. Northern and Central Great Plains. Remote Sensing of Environment, 65(1): 25-37. doi: 10.1016/ S0034-4257(98)00012-1

Yang Y H, Watanabe M, Li F D et al., 2006. Factors affecting forest growth and possible effects of climate change in the Taihang Mountains, northern China. Forestry, 79(1): 135-147. doi: 10.1093/forestry/cpi062

Yang Y H, Watanabe M, Wang Z P et al., 2003. Prediction of changes in soil moisture associated with climatic changes and their implications for vegetation changes: waves model simu- 
lation on Taihang Mountain, China. Climatic Change, 57(1-2): 163-183. doi: 10.1023/a:1022102510975

Yu F, Price K P, Ellis J et al., 2003. Response of seasonal vegetation development to climatic variations in eastern central Asia. Remote Sensing of Environment, 87(1): 42-54. doi: 10.1016/ s0034-4257(03)00144-5

Yu H, Luedeling E, Xu J, 2010. Winter and spring warming result in delayed spring phenology on the Tibetan Plateau. Proceedings of the National Academy of Sciences of the United States of America, 107(51): 22151-22156. doi: 10.1073/pnas.10124 90107

Zeng Xianzhi, Yang Yuejun, Zhang Guohong et al., 2010. On the Greening Project of Taihang Mountains. Forestry Economics, 7: 52-54. (in Chinese)

Zhang G H, Liu G B, Zhang P C et al., 2014. Influence of vegetation parameters on runoff and sediment characteristics in patterned Artemisia capillaris plots. Journal of Arid Land, 6(3): 352-360. doi: 10.1007/s40333-013-0224-5
Zhang Suqin, Ren Zhenqiu, Li Songqin, 1994. The influence of fluctuation of global temperature on precipitation in China. Quarterly Journal of Applied Meteorology, 5(3): 333-339. (in Chinese)

Zhang X, Friedl M A, Schaaf C B et al., 2005. Monitoring the response of vegetation phenology to precipitation in Africa by coupling MODIS and TRMM instruments. Journal of Geophysical Research: Atmospheres, 110(D12): D12103. doi: 10. 1029/2004JD005263

Zhao N, Yang Y, Zhou X, 2010. Application of geographically weighted regression in estimating the effect of climate and site conditions on vegetation distribution in Haihe Basin, China. Plant Ecology, 209(2): 349-359. doi: 10.1007/s11258-0109769-y

Zhou L M, Tucker C J, Kaufmann R K et al., 2001. Variations in northern vegetation activity inferred from satellite data of vegetation index during 1981 to 1999. Journal of Geophysical Research: Atmospheres, 106(D17): 20069-20083. doi: 10.1029/ 2000jd000115 